\title{
O POVO DA GEOGRAFIA COMO RESPOSTA NA POLÍTICA DE CURRÍCULO
}

\author{
The people of Geography as an answer to the curriculum policy \\ Hugo Heleno Camilo Costa* \\ *Professor do Instituto de Ciências Humanas e Sociais - ICHS / UFMT - hugoguimel@yahoo.com.br. \\ Recebido em 10/08/2018. Aceito para publicação em 25/08/2018. \\ Versão online publicada em 20/11/2018 (http://seer.ufrgs.br/paraonde)
}

\begin{abstract}
Resumo: A partir da abordagem ao significante interdisciplinaridade, busco compreender os processos de subjetivação da Geografia na tradução da política de integração curricular no nível médio. Volto-me às concepções de povo, pontuada por Ernesto Laclau, e tradução, pensada por Derrida, com vistas a afirmar a política de currículo como dinamizada por lutas discursivas, marcadas pelo antagonismo e pela exclusão. Para isto, situo também a perspectiva de currículo como texto, com foco nos trabalhos de Lopes e Macedo. Com esta leitura curricular, compreendo os sentidos produzidos para/pela Geografia no nível médio, no âmbito de uma construção também discursiva como a do currículo integrado. Concluo pela problematização da ideia de que subjetividade política da Geografia é uma provisoriedade de resposta formulada a partir de demandas a fazem ser frente à alteridade.
\end{abstract}

Palavras-chave: Políticas de Currículo; Ensino de Geografia; Teoria do Discurso.

\begin{abstract}
From the approach to the signifier interdisciplinarity, I try to understand the processes of subjectivation of Geography in the translation of the curriculum policy of curricular integration in the Secondary. I return to the conceptions of people, pointed by Ernesto Laclau, and a translation, thought by Derrida, to affirm the curriculum policies as dynamized by discursive struggles, defined by antagonism and exclusion. For this, I also draw attention to the perspective of curriculum as text, focusing on the works of Lopes and Macedo. With this curricular reading, I understand the meanings produced for / by Geography at the secondary, within a discursive construction as well as the integrated curriculum. I conclude by problematizing the idea that geography's political subjectivity is a provisional response formulated from demands that make it to be against otherness.
\end{abstract}

Key-words Curriculum Policy; Geography Teaching; Discourse Theory.

\section{O questionamento pela interdisciplinaridade}

Duas provocações trazem ao presente texto a preocupação em pensar a produção de políticas de currículo para Geografia. A primeira, que sustenta teoricamente este trabalho, é organizada no campo da teoria social e da filosofia política pós-marxista. Ela ganha consistência no argumento central da Teoria do Discurso de Ernesto Laclau (2011), qual seja o de que a política é dinamizada discursivamente por movimentos pró-hegemônicos que, por sua vez, são mobilizados na contingência e na volatilidade das identificações políticas. A segunda, e que também está envolvida com os argumentos da primeira, diz respeito à afirmação de Alice Casimiro Lopes (2008) de que, no Brasil, o nome interdisciplinaridade ganha vulto nos debates sobre a reforma do Ensino Médio via integração curricular.

Se com Laclau (2011) é possível conjecturar a impossibilidade de afirmações identitárias fixas, essencializadas ou anteriores à luta política, com Lopes (2008) temos o nome interdisciplinaridade na 
política que, dentre tantas hegemonias, constitui-se como mais uma, uma equivalência, que funcionaria como significante flutuante (LACLAU, 2011), que tende a introduzir a sensação de fechamento na política para o Ensino Médio. Dentre outras possibilidades, no que toca à Geografia, os dois argumentos oportunizam questionar sobre as vias estratégicas à investigação sobre a produção de políticas de currículo para a disciplina, levando em consideração o modo como se constitui na relação com o nome interdisciplinaridade.

Tal questionamento, a partir dos estudos mencionados, projeta a crítica aos pressupostos com que tendemos a operar na relação com a disciplina, como quando afirmamos determinada propriedade a partir de fundamentos epistemológicos e/ou de uma história condicionante, por exemplo. Contra uma eventual crítica niilista, baseada em uma redução de possibilidades interventivas e/ou argumentativas da disciplina na/à política, o questionamento acima também permite interpor a ideia de que, como resposta na política, a Geografia é precipitada, enquanto subjetivação política, frente ao nome interdisciplinaridade.

Com estes argumentos, focalizo a Geografia na política de currículo para o nível médio como resposta, como subjetivação contingente aos questionamentos de uma alteridade na política. Este enfoque visa chamar a atenção para a perspectiva de que o que lemos por uma atualidade da Geografia não é sustentado a priori da política, mas é uma articulação no que podemos entender como uma textualização mais ampla da política curricular. Isto é conceber a Geografia na política de currículo como um povo, ou seja uma cadeia de equivalências constituída por diferenças sociais que, em um aqui-e-agora contextual da política, são aglutinadas na oposição comum a algo lido como ameaçador. Nesse texto, proponho o nome interdisciplinaridade como isto/este com o que o povo da geografia se constitui em oposição. Um nome em relação ao qual a Geografia se constitui na política para o Ensino Médio.

Portanto, o que a Geografia responde na política de currículo à alteridade diz respeito ao modo como são interpretadas as possibilidades de 'ser' na própria política, de combater um dado ameaçador ao que, provisoriamente, julga ser uma propriedade, uma identificação.

Com vistas ao destaque dos trilhos por meio dos quais apoio esta argumentação, este trabalho está organizado de modo a destacar, em sua primeira seção, as preocupações teóricas que envolvem este texto, nas quais estão os referencias pós-estruturais e pós-marxistas do pensamento laclauniano e suas apropriações ao campo do currículo, desenvolvidas por Lopes e Macedo (2011). No trecho, procuro conjecturar a noção de povo como possibilidade interpretativa à subjetivação política em que se constitui o nome Geografia no Ensino Médio.

Na seção seguinte, chamo a atenção para os marcadores empíricos por meios dos quais destaco as formas de resposta/identificação da disciplina na textualização política. Para isto, lanço mão de trechos de documentos oficiais e entrevistas ${ }^{1}$, pensando-os como partes de um texto constitutivo da política que não se encerra em entrevistas ou documentos, não diz respeito a assinaturas de consultores, mas marcam momentos de um texto geral da política curricular.

\section{A decisão como precipitação do povo na política}

Como decorrência de pesquisa desenvolvida anteriormente (COSTA, 2013), na qual foi tensionada a tradição investigativa sobre a produção de políticas de currículo para uma disciplina, tendo na concepção de comunidade disciplinar (GOODSON, 1993; 1997) sua principal ancoragem, as apropriações teóricas da Teoria do Discurso de Ernesto Laclau (1996; 2011), que motivam este texto, visam o investimento na reconceptualização de formas interpretativas à constituição de subjetivações políticas a partir de aportes pós-estruturais.

Como discutido em Costa e Lopes (2016), este movimento não está pautado na crítica aos trabalhos de Goodson, mas nos limites que suas formulações teóricas apresentam quando pensadas no âmbito da investigação pós-estrutural. Por este motivo, a perspectiva laclauniana de povo, como alegoria à noção de cadeia de equivalência (LACLAU, 2011), foi incorporada com o objetivo de propor

\footnotetext{
1 Os entrevistados atuaram na elaboração dos documentos oficiais, na condição de consultores ou leitores críticos. Para preservação de seus nomes, são denominados aqui como Aretha, Stewart e Donna.
}

Para0nde!?, Porto Alegre, v.10, n.2, p.135-141, 2018. Edição Especial com artigos publicados originalmente na XII ENANPEGE http://seer.ufrgs.br/paraonde 
vias interpretativas com potência para afirmação de subjetivações políticas envolvidas com as disciplinas escolares.

Tal potência se diferencia de leituras essencialistas ou estruturantes, como a que nos propõe Goodson $^{2}$, ao acenar para a construção de subjetivações políticas marcadas pela contingência e precariedade, características da política em uma leitura discursiva. Um sujeito político, em Laclau (2011), estaria marcado pela incompletude e ausência de consciências transcendentais ou encarnação, não-determinado por epistemologias ou histórias condicionantes de suas decisões na política. Tal subjetivação, marcada pelo processo de nomeação, é lida como precipitada na luta política, no que Derrida (2001) assinala como um 'aqui-e-agora', sem precedentes, mas que impele à resposta, à decisão. Isto significa conceber as identificações políticas como decorrência de uma decisão na (própria) política, frente aquilo ao que se opõe, ao que é lido como ameaça ou impedimento à plenitude (nunca alcançada do ser).

Laclau projeta, dentre suas diferentes concepções, a ideia de povo, por meio do que busco pensar um povo da Geografia na política de currículo, ou seja, uma resposta como subjetivação em/através/pelo nome da Geografia no contexto da política de integração curricular em que se constitui um texto da reforma do ensino médio.

Laclau $(2005 ; 2006)$ pontua que a formação de um povo se dá a partir da equivalência estabelecida entre demandas heterogêneas, diferentes entre si. Uma unidade que não se constitui através de uma expressão ideológica, mas de uma relação entre demandas sociais insatisfeitas, uma pluralidade de demandas que passam a estabelecer determinado grau de solidariedade entre si. No momento equivalencial, de precipitação do povo, não é garantida fixação última desta subjetividade, mas é gerada uma sensação de fixação na articulação das demandas.

Para ele (LACLAU, 2005), a cadeia de equivalências debilita provisoriamente as diferenças, mas não pode detê-las. Igualmente, o autor acrescenta que as diferenças operam na cadeia equivalencial fundamentando-a e, ao mesmo tempo, estabelecendo uma relação conflituosa com ela. São, portanto, incompatíveis e interdependentes.

O povo disciplinar é constituído não por positividade, algo em comum, mas porque, em dada ocasião, há um exterior constitutivo, um inimigo comum antagônico. Argumento, então, que o povo é composto pelas subjetividades constituídas em operações provisórias no campo discursivo da disciplina. A disciplina é considerada, em concordância com Lopes e Macedo (2011), como construção discursiva que não possui saberes primordiais a serem apropriados pelos integrantes de uma comunidade que sem os quais dela estariam excluídos. Concordo que tais saberes são construídos ao passo em que nos tornamos disciplinares. Com as autoras, pontuo ser por meio de diferentes lutas políticas que hegemonizamos campos disciplinares e nos constituímos como identificação nessas lutas. As disciplinas, vistas sob esse prisma, não se vinculam ao processo de fixação de identidades, mas como campos discursivos, como subjetivações provisórias.

Nesse cenário, destaco a perspectiva de Laclau (2011), para quem, apesar da ausência de uma positividade, há a produção de uma "verdade" ou um valor capaz de cimentar a equivalência entre as diferenças articuladas. Essa 'verdade' não existe independente de um "contexto". Ou seja, a validade de todo pleito ou asserção só pode ser definida contextualmente. No entanto, por operar com a noção de pluralismo das diferenças e, se essas diferenças são constitutivas, surge a impossibilidade de definição dos limites sistemáticos de um contexto, além das diferenças em si. Ressalta-se, então, a inviabilidade de definição interna dos limites do contexto. Em função de tal entrave, Laclau (2011) defende que a única maneira de se definir os limites de um contexto é focalizar o que está 'para além' dos limites do contexto, o que implica enfatizar ao quê esse contexto se opõe.

Assim como a cadeia de equivalências, constituinte de um "povo disciplinar de Geografia", é um espaço de disputa contínua por significação, pela hegemonização de sentidos, não possuindo, portanto, um centro estável, a ameaça a qual ela se opõe também se constrói nessa perspectiva. Como as

\footnotetext{
2 Segundo Goodson (1993;1997), a comunidade disciplinar, como sujeito político produtor de políticas para uma disciplina escolar, seria compreendida pelos praticantes disciplinares (professores escolares e universitários, além de pesquisadores do campo disciplinar), cuja motivação estaria na aquisição de recursos, território curricular, prestígio e melhores condições de trabalho.
}

ParaOnde!?, Porto Alegre, v.10, n.2, p.135-141, 2018. Edição Especial com artigos publicados originalmente na XII ENANPEGE http://seer.ufrgs.br/paraonde 
diferenças articuladas na cadeia em foco não deixam de existir, mas limitam-se em função da equivalência que as subverte na articulação, destaca-se, como já mencionado, o caráter heterogêneo e instável da cadeia equivalencial e, assim, define-se o seu oposto, seu inimigo, da mesma forma. Se esse inimigo não é homogêneo, as identidades articuladas só podem estar traduzindo (COSTA, 2013; LOPES; CUNHA; COSTA, 2013) diferentes elementos como uma mesma ameaça, um nome catalisador da significação da ameaça, e, assim, articulando-se contra esse nome.

Dentre possíveis nomes da política de currículo, defendo ser por meio do termo "interdisciplinaridade" que um trecho do conflito pela hegemonia na política de currículo em foco se desdobra. Um nome continuamente traduzido, pensado aqui como um "significante flutuante", disputado, em princípio, por duas cadeias equivalenciais: a do "povo disciplinar da Geografia" e a do "discurso pró-integração curricular". Esse significante está submetido à pressão estrutural de ambas as cadeias, o que a leva a ter sua significação indefinida no sistema político (LACLAU, 2006). Para Laclau, a situação de competição equivalencial é que assinala o caráter flutuante do significante. A própria flutuação depende das lutas políticas entre demandas disciplinares e demandas pela integração curricular.

Ao compreender que a identidade de ambas as cadeias equivalenciais está em negociação no embate pela significação de "interdisciplinaridade", reitero sua focalização como forma de compreender, não só o modo como se constitui e determina a identificação do "povo disciplinar", como a identidade que esta projeta como antagônica. Além disso, penso que tal análise seja capaz de auxiliar na compreensão do que é projetado como uma falta à identidade comunitária da Geografia no cenário da política curricular para o Ensino Médio.

\section{0 povo da Geografia como resposta à alteridade}

Ao tempo em que a interdisciplinaridade pode ser lida como nome por meio do qual a integração curricular é viável (LOPES, 2008), este mesmo nome ganha, no âmbito dos documentos, sentidos disciplinares, sendo no caso da Geografia interpretado como característica do próprio campo. A flutuação deste nome na política, tal como discutido em Costa (2013), Costa e Lopes (2016), acena para uma operação em que é significado como apoio à integração curricular, como discurso crítico à organização do currículo por disciplinas; e, por outro, como potência de uma identificação da Geografia dentre as disciplinas da área de ciências humanas no nível médio.

Ao longo dos documentos dos Parâmetros e Orientações Curriculares Nacionais para o Ensino Médio (BRASIL, 1999; 2006), a interdisciplinaridade é lida como via capaz de levar à distensão disciplinar, à inovação, à formação de sujeitos supostos como demandados pelo mundo atual, à cidadania. Entretanto, nos trechos específicos para Geografia, são postos em circulação sentidos de interdisciplinaridade como marca do pensamento geográfico, como falta à consolidação científica da Geografia, como ciência, ou à suposição de sua fragilidade no âmbito das demais disciplinas.

Na negociação com o significante interdisciplinaridade, a articulação de diferentes sentidos pode dar base a uma visão interdisciplinar que se supõe como geográfica, oportunizando, simultaneamente, a geração de apoio ao discurso disciplinar e privilégio a uma suposta definição geográfica (integrada) de seu objeto de estudos. O "espaço geográfico" (BRASIL, 1999), é introduzido como sinalizador de uma perspectiva crítica do pensamento geográfico, é lido como possibilidade de alinhamento com as demandas de formação de indivíduos para o mundo atual.

Se por um lado a definição de seu objeto específico, somada à ideia de que a Geografia é uma "ciência autônoma" (BRASIL, 1999, p.29), possibilita a defesa de propriedades do conhecimento geográfico em relação às demais disciplinas, por outro lado, é ponderada a ideia de que a "Geografia em si já é um saber interdisciplinar" (BRASIL, 1999, p. 31). A partir dessa afirmação, ao apelar para a ideia de que o conhecimento geográfico é resultado de saberes diversos, são apropriadas discussões e reivindicações, em torno das quais o "povo disciplinar de Geografia" também se articula, como ao afirmar que "a Geografia muito pode auxiliar para romper a fragmentação factual e descontextualizada" (BRASIL, 1999, p. 32). 
Não só o conhecimento geográfico é dado como capaz de pensar as questões utilizadas como defesa à integração curricular, como ainda é matizado o seu caráter de integração de conhecimentos humanos e naturais ao atentar para questões ambientais. Opera, também, a ideia de que, no campo da Geografia, a interdisciplinaridade é vista como uma vantagem da disciplina, como ao ponderar que a disciplina "procura assumir hoje a interdisciplinaridade, admitindo que esta posição é profundamente enriquecedora. Conceitos como natureza e sociedade, por exemplo, se acham dilacerados entre várias disciplinas e necessitam de um esforço interdisciplinar para serem reconstruídos." (BRASIL, 1999, p.31-32)

Dentre as demandas, destaco a interpretação do conhecimento geográfico como capaz de responder aos questionamentos dirigidos às disciplinas quanto as suas possibilidades em lidar com o que se julga ser a atualidade da educação, a busca por uma consonância com as demandas do mundo globalizado. Deste modo, é possível interpretar a Geografia como atenta a tais problemas e, ainda, sugerir, como resposta à crítica às disciplinas, a habilitação da Geografia como campo produtor do conhecimento integrado. É possível inferir que, dentre outras oportunidades, há traduções possíveis de que a Geografia seja uma disciplina privilegiada no contexto de uma proposta de integração de conhecimentos, haja vista seu enfoque articulador do natural com o humano, logo uma visão interdisciplinar.

Com isso, pode-se, provisoriamente, desenhar um cenário em que o povo da Geografia, constituído nessa política, produz argumentos/traduções a partir do que se tem por pensamento geográfico. Argumentos que sustentam, buscam dar estofo às suas respostas/subjetivação, quais sejam as respostas às ameaças do currículo integrado, que podem ser pensadas como questionamento da validade do conhecimento disciplinar quanto a sua efetividade para uma visão inovadora de ensino. Esta visão poderia ser a da busca pela defesa e garantia de permanência do que se considera como Geografia, finalidade social, espaço de oportunidade, na política.

Traduções em defesa do currículo disciplinar e da hegemonia do conhecimento geográfico, como resposta aos argumentos "da ameaça" às disciplinas, à Geografia, são sentidos que penso estarem articulados na constituição do povo disciplinar. Deste modo, podem operar sentidos em defesa das disciplinas, significando-as como capazes de pensar o mundo de modo integrado, a despeito de leituras opostas. Há a leitura de que a Geografia, em relação às demais disciplinas, se estabeleceria de modo privilegiado no âmbito de uma preocupação interdisciplinar. Estas leituras são possíveis se também vinculadas às argumentações de Aretha, para quem a Geografia "é uma área propícia a um trabalho interdisciplinar (...) tem um olhar específico, o olhar da espacialidade. Mas como todos os fenômenos se manifestam espacialmente, você estuda todos os temas".

No que tange às Orientações (BRASIL, 2006), segundo Stewart, frente aos PCNEM e à proposta de ensino por áreas do MEC, a equipe buscou pensar um documento baseado na identidade da Geografia, a partir de questões como “(...) qual é a cara da Geografia? Qual é a independência, ou pelo menos, qual é o corpo da Geografia que a faz uma disciplina identificada? Quero dizer, que possa ser identificada pelos outros. 0 que é que nós temos de próprio, de característico?

Por outro lado, a Geografia é pensada como o próprio conjunto de conhecimentos que devem ser integrados, haja vista a significação das competências, mecanismos integradores, de forma disciplinar. Tal perspectiva se aproxima da visão de Donna, para quem "a interdisciplinaridade na Geografia é quando conseguirmos juntar a Geografia Física e Humana. Está aí a interdisciplinaridade da Geografia para mim. A integração é da Geografia e com a Geografia". Estes argumentos colocam a ideia de integração como tradução da interdisciplinaridade geográfica, focalizando-a como meta ou problema ao próprio pensamento geográfico. Desta forma, lançada às problemáticas geográficas, a integração via interdisciplinaridade é um meio de ruptura com o problema da fragmentação que caracteriza a reflexão geográfica, entendida como devendo se integrar na compreensão do mundo.

\section{Considerações finais}

O empreendimento deste texto tem por finalidade reiterar a potencialidade das contribuições do

\footnotetext{
ParaOnde!?, Porto Alegre, v.10, n.2, p.135-141, 2018. Edição Especial com artigos publicados originalmente na XII ENANPEGE
} http://seer.ufrgs.br/paraonde 
pensamento pós-estrutural, particularmente da Teoria do Discurso de Laclau, para a investigação das políticas de currículo para Geografia. Penso tais contribuições como oportunidades à releitura do modo como são mobilizadas, discursivamente, dinâmicas de afirmação do social, da maneira como a Geografia é subjetivada na política, do modo como são lidas possibilidades de resposta na política.

Com este trabalho, também penso possibilitar a concepção de que a produção de políticas de currículo para a disciplina não está restrita a determinações da ciência, de demandas escolares, ou somente da militância de sujeitos pré-concebidos em prol de benefícios corporativos. Mas, interessa a defesa de que as diferentes e conflituosas formas de significação da Geografia, nos momentos da política que argumento fazerem parte de uma textualização mais ampla da política, dizem respeito ao modo como são interpretadas oportunidades de intervenção política na relação com uma alteridade desconhecida. Uma alteridade da política que suponho como questionadora de um vir a ser Geografia. Um porvir cujas respostas sintomatizam o desespero de uma identificação política que, na contemporaneidade de suas afirmações dá conta de recuperar matizes e perspectivas de diferentes ordens com vistas ao estofamento de uma resposta possível ante ao desafio ou ameaça na política.

Ao menos no que interpreto como luta pela estabilização do antagonismo, entre a integração e o disciplinar, focalizo a tradução de sentidos do outro como possibilidade de existir e, nessa leitura, afirmar uma propriedade, que se constitui provisoriamente como aquilo que é suposto como questionado pelo outro, algo de que se depende para continuar. Penso que esta noção auxilia na compreensão dos desenhos da política, muitas vezes considerados contraditórios, desorganizados epistemologicamente, incoerentes em suas propostas, aleatórios ou ecléticos (OLIVEIRA, 1999). Argumento que se as subjetivações se dão pela referência a uma ameaça, visando responder aos seus questionamentos, e se estes questionamentos não são os mesmos, mas traduções do que se pensa ser a ameaça, já se pode supor que a agitação pela construção de respostas "plausíveis" não diz respeito a questões de determinação epistemológica, corporativa ou essencial.

A cadeia equivalencial em que se constitui o povo da Geografia não obedece a determinações apriorísticas, mas as dos sentidos dados pela leitura do outro. Em função dele, traduz o que na atualidade da resposta se the apresenta como tradição, conhecimento, habilitação, visão de mundo possível a ser significada como a si mesma. Por esta razão, argumento que, quando traduzida em outros contextos, a política pode ser vista como non-sense, perspectivas de Geografia podem ser entendidas como assimétricas ou problemáticas quando expostas à referência de outros contextos como, por exemplo, o do que se pode entender por Pensamento Geográfico, em dado momento, como em Oliva (2006), Oliveira (2009) e Castellar (2005), por exemplo.

Nessa política, a busca pela significação do que é disciplinar como alinhamento ao que se julga ser um problema atual, esse próprio "mundo atual/integrado", como refutação do que é "disciplinar/antiquado/estanque", se sustenta/existe pela interpretação de um outro que é julgado como impedimento, bloqueio, ameaça. Nessa escrita a muitas mãos, o disciplinar, que pode ser pensado pela Geografia como retrato de si, pode estar sendo significado/defendido como capaz de responder aquilo que lhe coloca em risco, que se desenha como impedimento a ser, a viver, a continuar. Nesse contexto, de muitos acontecimentos, considero a busca pela significação interdisciplinar da Geografia como meio de denegar o caos gerado pelo acontecimento dos sentidos de integração curricular, que podem ser interpretados como negação às disciplinas e, portanto, negação à Geografia.

Traduzir este nome (Geografia) como interdisciplinaridade e, assim, suscitar canais que oportunizem sua vinculação a sentidos que conjecturem a interdisciplinaridade como defesa à integração pode, simultaneamente, sustentar momentos de sensação de estabilidade, novas traduções e oportunidades, precárias e provisórias, para aplacar o tremor causado por essa "ameaça/alteridade" em que pode se constituir o nome integração curricular.

Mas, por outra mão, pode favorecer leituras agressivas aos campos disciplinares, às contribuições de formas de ler o mundo como a Geografia, ao apoiar a suposição de que, por diferentes motivos, um currículo organizado por áreas seria mais proveitoso e inovador para determinada visão de conhecimento, formação para dado horizonte de vida/sociedade/cidadania/trabalho/inclusão/cultura. 
Tomando por emblemáticas as discussões atuais em torno da BNCC 3 , do Ensino Fundamental ao Médio, podemos ter a projeção de tais conflitos pela organização curricular como um movimento de continuidade ou agudização de determinada visão curricular reformista. E, eventualmente essencializando ainda mais esta afirmação, poderíamos atribuir a uma identidade este conjunto de propostas. Entretanto, em um investimento de não-essencialização, importa questionar se distintas identificações políticas articuladas à Geografia também não estariam traduzindo diferentes nomes/termos na política como características da disciplina e, assim, contribuindo para a manutenção deste conflito. Longe da proposição de formas de distinção do que é ou não de propriedade/domínio da Geografia ou do Currículo, a aposta deste artigo é, também, acenar para o conflito, como possibilidade de estar na luta pela significação do que é e/ou pode ser a Geografia na escola, como um horizonte político interessante.

\section{REFERENCIAS}

BRASIL. Parâmetros curriculares nacionais: Ensino Médio. Brasília: MEC/Semtec, 4v, 1999.

. Orientações Curriculares Nacionais para o Ensino Médio. Secretaria de Educação Básica. Brasília: Ministério da Educação, Secretaria de Educação Básica, 2006.

COSTA, H. H. C.. O povo de Geografia e a política de currículo: tradução e originalidade. Periferia (Duque de Caxias), v. 6, p. 103-116, 2014.

LOPES, A. C.; CUNHA, E. V. R. ; COSTA, H. H. C. . Da recontextualização à tradução: investigando políticas de currículo. Currículo sem Fronteiras, v. 13, p. 392-410, 2013.

COSTA, H. H. C.; LOPES, A. C. A comunidade disciplinar em Goodson: impasses em um registro pósestrutural. Revista Brasileira de Educação, v. 21, p. 1009-1032, 2016a.

COSTA, H. H. C.; LOPES, A.C. A Geografia na política de currículo: quando a integração reafirma a disciplina. Pró-Posições (UNICAMP. Online), v. 27, p. 179-195, 2016b.

DERRIDA, J. Posições. Belo Horizonte: Autêntica, 2001a.

GOODSON, I. School subjects and curriculum change. Londres: The Falmer Press, 1993.

A Construção social do currículo. Lisboa: Educa, 1997.

LACLAU, E. La razón populista. Buenos Aires: Fondo de Cultura Económica, 2005.

Inclusão, exclusão e a construção de identidades. In: AMARAL, JR. A.; BURITY, J. (org). Inclusão social, identidade e diferença perspectiva pós-estruturalista de análise social. São Paulo: ANNA BLUME, 2006.

LOPES, A. C.; MACEDO, E. Teorias de Currículo. 1. ed. São Paulo: Cortez, 2011a. v. 1. 279p.

\footnotetext{
${ }^{3}$ Para acesso a proposta do Ensino Médio e aos debates em torno desta política, sugiro, respectivamente, acesso aos sites: http://basenacionalcomum.mec.gov.br/bncc-ensino-medio e http://cnebncc.mec.gov.br/ . Acessados em 10 de agosto de 2018.
} 